\title{
Anger and Contested Place in the Social World
}

\author{
Warren D. TenHouten \\ Department of Sociology, University of California, Los Angeles, CA, USA \\ Email: wtenhout@g.ucla.edu
}

How to cite this paper: TenHouten, W. D. (2018). Anger and Contested Place in the Social World. Sociology Mind, 8, 226-248. https://doi.org/10.4236/sm.2018.83018

Received: April 27, 2018

Accepted: June 2, 2018

Published: June 5, 2018

Copyright $\odot 2018$ by author and Scientific Research Publishing Inc. This work is licensed under the Creative Commons Attribution International License (CC BY 4.0).

http://creativecommons.org/licenses/by/4.0/

\begin{abstract}
The root term angr includes in its meaning anger-rage and sadness-grief, which today are recognized as two primary or basic emotions. Anger involves the brain's "rage system", an architecture widely represented in the animal kingdom. Anger and its opposite, fear, are the positive and negative adaptive reactions to the existential problem of social hierarchy and associated competition for resources and opportunities. Anger's valence can be negative insofar as it is unpleasant for all involved but is primarily positive because anger is goal-seeking and approach-oriented. Anger functions to assert social dominance, and detection of anger in others reveals possible challenge intentions. The management and control of anger is linked to impulsivity, patience, and tolerance. While the Russell-Fehr model views emotions such as aggressiveness, sullenness, and resentment as subcategories of anger, we rather contend that anger is an embedded subcategory of secondary- and tertiary-level emotions. We model one such emotion, resentment, as a tertiary emotion. Resentment has anger as its key emotion, and includes the primary emotions disgust and surprise, which can combine in pairs to form outrage, contempt, and shock. A classification of 7 secondary and 21 tertiary emotions in which anger is embedded is presented. We argue that the classification of complex emotions is a potential, and necessary, project for the sociology-anthropology of emotions.
\end{abstract}

\section{Keywords}

Anger, Fear, Sullenness, Emotions Classification, Social Dominance

\section{Introduction: Anger, Fear, and Sadness}

In the oldest record of European culture, in first sentence of Homer's Iliad, we find "Mênos aidede, thea, Peleiadeo Achileos...", where Mênos (anger, rage, wrath), used as a noun in the accusative case, becomes the first word of the Western tradition. The Iliad is largely the story of Achilles' anger, rage, or wrath, 
a "baleful force" which "unleashes its power on all sides", as his anger turned him against his own people, as he fought on the Greek side only before the decisive battle (Sloterdijk, 2006). The struggle to control anger was crystallized in the moment when an enraged Achilles reaches for his sword to slay King Agamemnon, who had just dishonored him by announcing his intention to seize his prized concubine, Bresius. At this moment a materializing immortal, Phoibus Apollo, descended from Mount Olympus and urged him to restrain his anger. The concept of thumos, or spirited competitiveness, was used extensively in the Iliad to describe the emotion-laden character of those who participated in the siege of Troy, but Achilles anger was not synonymous with his thumos, for he also manifested thumos in expressing sadness at the death of his friend Patroclus at the hands of Hector, and shared pity and sorrow with the Trojan king Priam, whose son Hector he had vengefully slain. Sloterdijk's description of rage as "baleful", together with the meaning of thumos as spanning anger and sadness, suggests that anger-rage is linked to sadness-grief, and that anger and sadness mix to form a more complex emotion, "balefulness", an anguished state of mind that can be further described as a dysphoric sullenness (TenHouten, 2013: pp. 131-137, pp. 200-203).

The historical linkage of anger and sadness is also evident in the entomology of the word "anger". The Old Norse word angr was derived from the Proto-Indo-European angh-. As the root of both "anger" and "anguish", angr meant distress, grief, sorrow, and trouble. The English word "anguish" has been traced to the Latin word angor. Anger today is understood as an anguished, stressful, and troublesome emotional state. It elicits mobilization for potential action to defend the self and its place in the social world, assert one's freedom to act, access resources, and compete for positions of social dominance. Anger ranges in intensity from mild irritation or annoyance, to furious rage. The term "rage" derives from the middle French/English word rabia, meaning rabies. "Rabies" (in French, rage) is an infectious disease that can cause blindly irrational behavior, madness, and death. The English word "rabid" in French means furieux, féroce, and enrage (furious, ferocious, enraged). While rage is often but not always a pathological form of uncontrolled anger, not all rage is pathological (DiGiuseppe \& Tafrate, 2007). Rage is a naturally occurring phenomenon, and anger and rage are differing levels of intensity of the same emotion. The brain's "rage system" involves primitive subcortical brain circuitry that humans share with a wide variety of other animal species (Panksepp, 1998: pp. 187-205; Panksepp \& Biven, 2012: pp. 145-175, pp. 191-205). In this view, emotions such as anger have a noncognitive infrastructure that, when activated, might or might not lead to cognitive activity; this primitive circuitry, in turn, can be activated through cognitive appraisal of one's situation (Lerner \& Tiedens, 2006).

Darwin ([1872] 1965: p. 239) provided a rich description of the physiology of anger: When a human being is in a highly angry state of mind, furious and enraged, "the body is commonly held erect for instant action, but sometimes it is 
bent forward toward the offending person". The forehead is apt to be furrowed, and the eyes intently directed forward, becoming bright, glittering, and protruding, with pupils contracted. The mouth might be tightly closed, or open to reveal clenched teeth, possibly with one lip retracted in a sneer. The face reddens or even becomes purple. The veins on the forehead and neck are distended, the hands are restless, and the fists are apt to be clenched. Body tension is high, and the posture crouching (Darwin, [1872] 1965: p. 74). The enraged individual is ready to fight for well-being, survival, or social dominance, and is fully mobilized for strong and effective action with a reduced sense of fear. Anger's physiological effects of include increased heart rate, blood pressure, and levels of the energy hormones, adrenaline and noradrenaline (Panksepp, 1998: pp. 187-205).

Darwin ([1872] 1965: pp. 136-143) saw strong linkages between anger, aggression, and dominance seeking. He suggested an evolutionary linkage between human anger and anger in lesser species, offering analysis of various monkey species. In its basest form, anger is indeed a primitive, exciting emotion with a long evolutionary history. "Anger and rage are psychobiological reactions to an actual or perceived insult or threat to the integrity and dignity of an individual or group" (Diamond, 1996: p. 15). While this emotion, anger/rage, is animalistic and primordial, it is far from becoming vestigial, "precisely because there do in fact continue to exist such insults, impediments, stumbling blocks, hindrances, and threats of our well-being, psychological growth, vocational satisfaction, and spiritual development" (Diamond, 1996: p. 15). We are all, and always will be, as Shakespeare's Hamlet opined, susceptible to the "slings and arrows of outrageous fortune".

We will describe two other basic emotions, fear and sadness, in relation to anger, consider the problematic valence of anger, link anger to social power and social dominance hierarchy, and then address the place of anger in emotions classification: To this end, we will identify anger as one of eight primary emotions, define the 7 secondary emotions combining anger and the other primary emotions, and then define the 21 tertiary-level emotions in which anger is embedded as a component.

\subsection{Anger and Fear}

Fear is the prototypical affective reaction assessing danger and protecting the self from harm. Fear motivates escape or flight behavior, and avoidance of strangers, hostile or predatory others, and dangerous physical situations. Emotions researchers describe a close connection between anger and fear. When a person is attacked, "the immediate reaction is fear and not anger" (Davis, 1983: p. 4). Fear is painful both psychologically and physiologically as well and manifests in sweating, trembling, retching, cramping, and vasomotor upset. Anger can function as "the usual defense against fear. If a reckless driver nearly hits us, for instance, we feel in that moment a blinding spasm of fear, a terror of death. Immediately afterward, anger sweeps over us. The anger blots out our fear ("That 
s.o.b.!"); it is counter-phobic (against fear)" (Davis, 1983: p. 5). A defensive form of anger thus functions to inhibit fear.

The most primordial experience of anger results from the perception of physical, psychological, or social restraints or blockages. Efforts to escape restraints require a (positive) exercise of power, which is necessary for overcoming a fear-induced state of powerlessness (TenHouten, 2016). Any kind of restraint, including rules and regulations governing social behavior, can trigger anger. Anger, a culturally-universal emotion, is everywhere linked to efforts to exercise power and/or to overcome frustrating impediments to free movement in spaces and places. "Fear-like frustration is a fundamental factor in the genesis of anger, rage, and violence. That which we fear, for whatever reason, can quickly become that which angers or enrages us, sometimes eliciting aggressive or violent behavior" (Diamond, 1996: p. 35). Moreover, "when fear and intimidation are felt persistently, they may turn to anger" (Walton, 2004: p. 45).

When people are aggrieved and troubled, they are roused to an active state provoked by the source of grievance. While fear is passive and trouble-avoidant, anger is a driving, compulsive force that encourages action. Indeed, "The most complicated and intricate linkage is that one between anger and fear. It is almost impossible to discuss anger without discussing fear. ... It is almost impossible to locate either one of these emotions in an instance of human behavior without find the other lurking in the background" (Gaylin, 1989: p. 56). A sustained provocation impels us to a passionate emotion, the intense kind of anger that we call "rage" or "fury". An individual faced with the rage and fury of another will react with the opposite emotion, fear, which when intensely experienced can reach the level of "terror". Thus, anger and fear form a unity of opposites, as they are the positive and negative adaptive reaction to the challenges of social power, play the functions of "destruction" and "self-protection", and involved the behaviors of "moving-toward" and "moving-away-from" (Plutchik, 1962). If anger and fear are experienced together, these tendencies for movement in space can cancel each other, as one cannot advance and retreat in the same moment, so that the resulting secondary emotion is a state of frozenness or tonic immobility (TenHouten, 2007: pp. 105-107).

\subsection{Anger and Sadness}

Sadness functions as the basic emotional reaction to the degradation or loss, be it temporary or permanent, imagined or real, physical or psychological, of a valued informal social relationship. Sadness can lead to social withdrawal and a state of lethargy. Separation from, or loss of, an object of attachment means loss of a source of joy and excitement, loss of affection, loss of security, and a reduced sense of well-being. If sadness is intense, as with the death of, or separation from, a valued other or family member, the struggle to cope with such a loss is best described as grief, which in this sense is technically not an emotion but a sentiment (Lazarus, 1999: p. 656). Sadness can also result from loss of self-attractiveness or vigor, loss of sensory or motor capability, loss of memory, loss of money or 
treasure, even loss of one's homeland.

Sadness can lead to anger and aggressiveness directed to others (Finman \& Berkowitz, 1989; Berkowitz, 1993). Anger following depression can result either from as mixing of negative affective states such as sadness and depression, or represent a shifting from one emotion to another, for example, from sadness to anger. In naturalistic settings of the occurrence of emotions, when respondents report they had feel sad, they are also likely to indicate they felt angry as well (Wickless \& Kirsch, 1988). That conditions and situations which elicit sadness are apt to also elicit anger, so that it is not unusual for infants separated from a primary caregiver to respond with both sad and angry expressions (Termine \& Izard, 1988). Sadness, at the level of grief, can also activate an anger-aggression syndrome. The emotions literature is replete with accounts of anger in those grieving over the death of a love one (Berkowitz, 1990: p. 496), and bereaved individuals not only become angry but on occasion engage in violent acts (Rosenblatt, Jackson, \& Walsh, 1973: p. 271).

Berkowitz $(1990,1993)$ contended that virtually any kind of negative affect will activate the anger-aggression syndrome. This is an overgeneralization. For example, anger does not ensue from a state of apathetic depression (Clore et al., 1993). Moreover, it is more accurate to say that emotions arise as (hopefully) adaptive reactions to social situations and ongoing social relations. Thus, if anger quickly follows sadness, we might hypothesize that the sadness follows from a social situation in which something close and personal has been lost, and the subsequent anger from the further realization that one's position in a social situation has, as a result, been negatively affected. Thus, if anger quickly follows sadness, it is not that sadness causes anger, but rather that personal loss results in sadness, which creates a loss of position in a network of social relations, which in turn triggers anger.

Thus, a complex social process can involve both a desire for positive action with respect to a situation of social hierarchy and a negative experience of close and personal relationships. Anger and sadness are very different emotions, and their co-occurrence can lead to a dysfunctional immobility, to a baleful and sullen state of mind. The great irony of the Iliad was that Achilles, renowned for being fleet of foot, ended up not enjoying combat but sulking, and off his feet, in his tent. While sadness is a negative experience felt loss of close and personal relationships rendering one gloomy and socially withdrawn, the sullen person can be further described as "baleful, threatening", which is behaviorally consistent with anger. The term "baleful", by itself, conveys these same two primary emotions, as the Webster Dictionary (Neufeldt \& Guralnik, 1988: p. 105) defines balefulness as containing both sadness ("sorrowful, wretched") and anger ("harmful or threatening harm or evil; ominous; deadly").

\section{The Valence of Anger}

Anger in everyday life is typically, but not necessarily, an unpleasant experience 
for both the angering and the angered. Expression of anger brings about a discontinuity in social life, and together with fear and sadness-grief, have been described as "dark emotions", and contrasted to "lighter emotions", such as joy and serenity, which bring continuity to life (Bailey, 1983: p. 37). Numerous emotions researchers assign anger a negative valence due to its adverse eliciting conditions, as it occurs in situations incongruent with one's goals (see Tomarken \& Zald, 2009: p. 135; for a review, see Ben-Ze'ev, 2000), troublesome moments in social relations, and as an emotion apt to diverge from other emotions in problematic situations involving judgment and decision making (Lerner \& Tiedens, 2006: pp. 129-132).

Anger is typically triggered in response to the behavior of another person who is perceived of as unjustifiably and deliberately threatening harm to one's place within a web of social relations (Aristotle, [355 BCE] 2002; Averill, 1982; Frijda, 1986). Such behavior it apt to be experienced by the one angered as an effort to downgrade or damage his or her social status, rank, position, or reputation. To refute the other's perceived unjust aggressive behavior, the aggrieved person mobilizes anger, and thereby "stands up", either for himself or herself or on behalf of valued other persons. Most generally, anger is a re-assertive response to goal-blockage or denigration (Carver \& Harmon-Jones, 2009). Anger can arise from frustration, but it can also signify and affirm a passionate commitment to one's fundamental values and goals. Anger can also arise when something bad happens to an individual, where no improper or malicious behavior of others is involved (Berkowitz, 1993: p. 3).

Anger is a positive emotion insofar as it is approach-oriented and goal-seeking emotion that prioritizes the attainment of favorable outcomes (Tomarken \& Zald, 2009). This positive aspect of anger was emphasized by Plutchik (1962, $1970,1980)$, who saw anger as the primary adaptive reaction, a "moving toward" an objective or goal in a social hierarchy. Anger has subsequently been linked to the "behavioral approach system" (Coan, Allen, \& Harmon-Jones, 2001), which is the motivational system that manages appetite, incentive motivation, and approach behavior (Cacioppo \& Bernston, 1994; Depue \& Iacono, 1989). Anger, as a goal-directed, approach-oriented, positively-valenced affect has also been referred to as "determination", meaning it contributes to a commitment to meet one's goals (Harmon-Jones et al., 2011). As stated by Panksepp (1998: p. 189), "The aim of anger is to increase the probability of success in the pursuit of one's ongoing desires and competition for resources".

Among humans, the approach-oriented nature of anger is visible even in infancy (He et al., 2010). While not observed in newborn humans, anger finds early expression: Even a ten-week-old infant will respond differently to an angry face than to a sad face (Haviland \& Lelwica, 1987). The ability to express anger marks a new and distinct stage in the development of social being. The first negative infantile affects are distress and disgust reactions. Gradually, restraining or frustrating situations motivate attempts to remove restraints and barriers. Such responses, typically developing at about 5 - 6 months of age, are the infant's first 
nonreflexive motor acts functioning to reduce negative affect through direct manipulation of objects, especially of primary caregivers. These acts of anger (usually and hopefully) enable the infant to remove restraints and circumvent barriers, thereby increasing the sense of self as a being separate from others and fostering awareness of self as a causative agent (Izard, 1980). The infant thus advances from a response of merely crying for help from others, to taking direct action through anger, so that the self-as-agent is experienced as being different from, and sometimes in opposition to, those who restrain or withhold.

A neurobiological generalization holds that the human brain's right and left hemispheres are respectively activated by unpleasant (and on this basis, "negative") and pleasant (and "positive") emotions (Heller, Nitschke, \& Miller, 1998). This generalization would suggest that anger disproportionately activates the right hemisphere's prefrontal networks. However, available evidence indicates that anger rather activates the left hemisphere's prefrontal networks. Davidson (1995) has hypothesized that the brain's left and right anterior regions are key components of an affect regulation system for approach- and avoidance-related behaviors; the left hemisphere's frontal lobe cognizes approach-oriented, "offensive" emotions, such as anger and happiness, while the right hemisphere cognizes avoidance-oriented, "defensive" emotions. This laterality difference can be seen in the warrior who holds his shield in his left hand (controlled by the right hemisphere) and his sword in his right hand (and left hemisphere). Carver \& Harmon-Jones (2009) investigated hemispheric asymmetry in response to emotional experience, finding that anger does not reflect an emotion's unpleasantness or pleasantness, but rather whether the emotion is approach-motivated or avoidance-oriented. Accordingly, anger should (and does) activate the left hemisphere's frontal lobe, because anger is clearly an approach-oriented emotion.

\section{Anger and Social Power}

The linkage of social power to anger is supported by a body of research showing that social status is enhanced by the expression of anger (Tiedens, 2001), and correspondingly, that high-status, high-power individuals are expected to display more anger than those less powerful in problematic situations (Tiedens, Ellsworth, \& Mesquita, 2000). Individuals who are social dominant manifest anger to which subordinate can but fearfully acquiesce (TenHouten, 2016). Individuals occupying high positions in complex organizations typically are high on social-dominance orientation (SDO), meaning they endorse the proposition that some groups should be dominant over other groups, and are attuned to social status as a basic organizing feature of social life (Pratto et al., 1994; Sidanius \& Pratto, 2001). Individuals low on SDO are rather oriented toward egalitarian social structures, with group equality being an ideal and legitimate organizing principle of social life. Ratcliff et al. (2012) hypothesized, and found, that as a means of detecting potential threats and challenges to their valued high positions 
(Russell, 1980), high-status and high-SDO individuals are attentive to expressions of anger in other high-status individuals. This attentiveness was interpreted as due to an understanding that high-status others will act on their own anger in a manner than contributes to their attainment or maintenance of social dominance positions This anger-detecting ability was most apparent among those who both occupy positions of dominance and endorse beliefs consistent with a social-dominance orientation.

In organizational contexts, research has shown that anger displays lead to more perceived power than do sadness displays. However, expressions of anger on the part of the powerful are not necessarily effective and sadness displays, perhaps expressing disappointment in the work performance of subordinates, can result in more positive leadership outcomes. Whereas angry leaders typically exercise positional power, sad leaders' power is rather based more on their personal attributes (Schwarzmüller et al., 2017). Thus, while anger is indeed an approach-oriented emotion, and like all emotions motivates adaptive reactions to social situations, anger expression is not always the best approach to others and can have unfortunate consequences (Van Kleef \& Côte, 2007). In some circumstances involving social power, another emotion that might be more adaptive than anger is happiness. Research has shown that negotiators with little power concede more to angry opponents than to happy ones, but high-power negotiators do not cave in to displays of anger. It can be a mistake to direct anger at an opponent possessing social power, for a non-threatening, good-natured, even happy presentation of self might be more effective (Van Kleef et al., 2006).

Anger, on the behavioral level, is a moving toward a person, object, or goal with the intention of removing impediments or obstacles to success, maintaining self-esteem and social status, or rectifying undeserved, unjust treatment. Anger is often directed toward the specific actions of another person or group of persons considered responsible for some unwarranted offense which is not only unjust but also challenges one's position or status. Displays of anger are in many social situations inappropriate and unjustified, as when the volitional actions of others might violate undermine the moral basis of a fair competition for the acquisition of a position of importance or social power. Intentional harm done to one's social standing is apt to be taken as a personal affront, an insult, or as a specific act constituting unfair or bad treatment on the part of another person. The resulting angry response would be fully justified but is apt to be met with counter-anger. Thus, one's initial angry outburst, met by counter-anger, can lead to a situation in which an argument ensues, wherein claims of rights and statuses are challenged, refuted, and renegotiated, and blame is assigned.

Anger can serve to readjust and strengthen interpersonal relationship. Two people who argue and express anger at each other are apt to experience angry outbursts as distressing and unpleasant in the short run but potentially beneficial to their relationship in the long run. Thus, anger can provide the basis for reconciliation on new terms (LaFollette, 1995: p. 199). Such arguments are apt to 
gain intensity beyond any single provocation, because it might well be the case that, for both parties, a long sequence of angering events have been remembered, stored up, embellished, exaggerated, distorted, but nonetheless "cumulated" as "savings", as if placed in an "anger bank", the contents of which can be "withdrawn" in a single "transaction" and in a way that lends importance and intensity to an episode of anger, counter-anger, counter-counter anger, amid bitter recriminations and hurtful, shaming gestures and remarks intended to gain "revenge" for "entries" on a remembered "list" of slights and transgressions (Sloterdijk, 2006; see also Scheff \& Retzinger, 1991).

In social-dominance encounters anger can be used in various ways. It can be strategic for a participant either to express anger or feel angry but conceal and, if necessary deny being angry. It is also valuable to detect anger in others by perceiving their facial expressions, gestures, postures, and verbalizations. To preserve or enhance one's position in an organizational context, a display of anger by another role incumbent can signal a possible threat to one's own position and provide insight into the other's thought and intentions. Anger is of central importance to power-based social relations, as it is highly arousing and can be employed strategically as an assertion of one's power, or indicate a challenge (Russell, 1980; Adams et al., 2006). Just as it is adaptive to recognize anger in others, so it is non-adaptive to not recognize such anger, "for not seeing or understanding the angry glare coming from your boss, friend, or partner could lead to negative consequences” (Ratcliff et al., 2012: p. 1373).

\section{Anger as a Primary Emotion}

Among emotions researchers who admit the existence of foundational, elementary, basic, or primary emotions, nearly everyone beginning with Alexander Shand (1914) has included anger (or rage). In Plutchik's (1958, 1962, 1970, 1980) psycho evolutionary theory of the emotions, four pairs of positively- or negatively-valenced primary emotions and their associated functions are modeled as adaptive reactions to four problems of life. These existential problems are: social identity (acceptance-incorporation/disgust-rejection) temporality

(joy-happiness/reproduction, sadness-grief/reintegration), territoriality (anticipation-exploration/surprise-orientation), and hierarchy

(anger-destruction/fear-protection). Plutchik's model is illustrated in Figure 1. This model sees anger as an offensive reaction, fear as defensive. Anger and fear can be conceptualized as the positive and negative poles of the social hierarchy dimension. This theoretical model shows the close relationship between anger and fear, links them to social hierarchy, and enables classification of secondaryand tertiary-level emotions formed from mixtures or combinations of eight primary emotions.

Affect-spectrum theory (TenHouten, 2007, 2013, 2017b) generalizes Plutchik's four existential problems into the four social relations specified in relational-models theory (Fiske, 1991, 2004). Thus, temporality generalizers into 


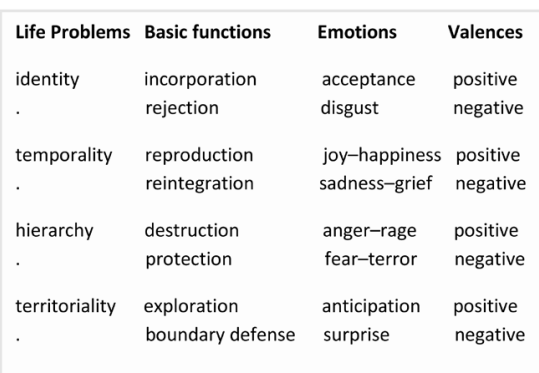

(a)

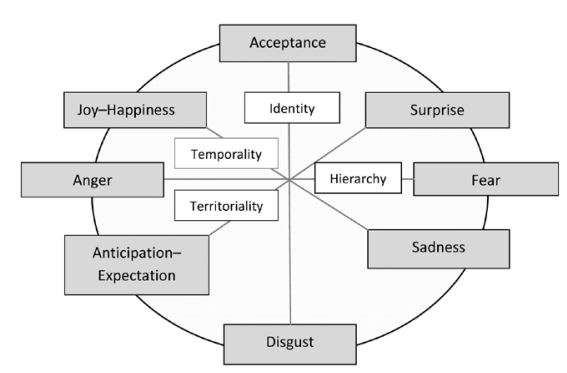

(b)

Figure 1. (a) Plutchik's model of the primary emotions; (b) Plutchik's circumplex or "wheel" of the eight primary emotions. Source: W. D. TenHouten. Alienation and affect. New York: Routledge, p. 63, fig. 5.1.

communal-sharing (CS), identity in equality-matching (EM), territoriality into market-pricing (MP), and hierarchy into authority-ranking (AR). These positively- and negatively-valenced social situations are then linked to the primary emotions. Thus, CS+ and CS- are linked to joy-happiness and sadness-grief, respectively; EM+ and EM-, to acceptance and disgust; MP+ and MP-, to anticipation and surprise; and $\mathrm{AR}+$ and $\mathrm{AR}-$, to anger and fear.

\section{Anger Embedded in Secondary and Tertiary Emotions}

The idea of basic or primary emotions as the building blocks of more complex emotions can be illustrated by considering a single example, that of "resentment", a term derived from the Old French recentement (1300) and the Middle French ressentiment (1613), meaning a true recall of an earlier experienced feeling or sentiment of any kind, including joy, sorrow, and grateful appreciation (Oxford online dictionary: meaning 2a). This broad meaning is obsolete, as resentment no longer refers to recall of sentiments in general, but only to negative sentiments relating to grievances, injuries, patterns of unfair treatment, and more generally unjustified harsh treatment at the hands of others. Even with this specification, resentment remains a complex emotion, which has hypothesized to be a tertiary emotion with the primary components anger, surprise, and disgust, and the secondary components outrage (anger \& surprise), contempt (anger \& disgust), and shock (surprise $\&$ disgust) (TenHouten, 2017a: pp. 113-119), as shown in Figure 2.

If, in comparison to other people, groups, or even to themselves at different points in time, individuals who believe they do not have what they, or their group, deserves, and feel at least relatively deprived, will feel anger and resentment. There is thus a close relationship between anger and resentment; it can be said that anger is the central ingredient of resentment. While in their meta-analytic review of relative deprivation theory, Smith et al. (2012: pp. 217-218) repeatedly refer to "angry resentment", but at the same time point out the difference between the two emotions. Resentment is a less ephemeral and more clearly moral emotion (that is, a sentiment) than is simple anger (see Grant, 2008).

The resentful person will feel anger at having been violated, mistreated, or 


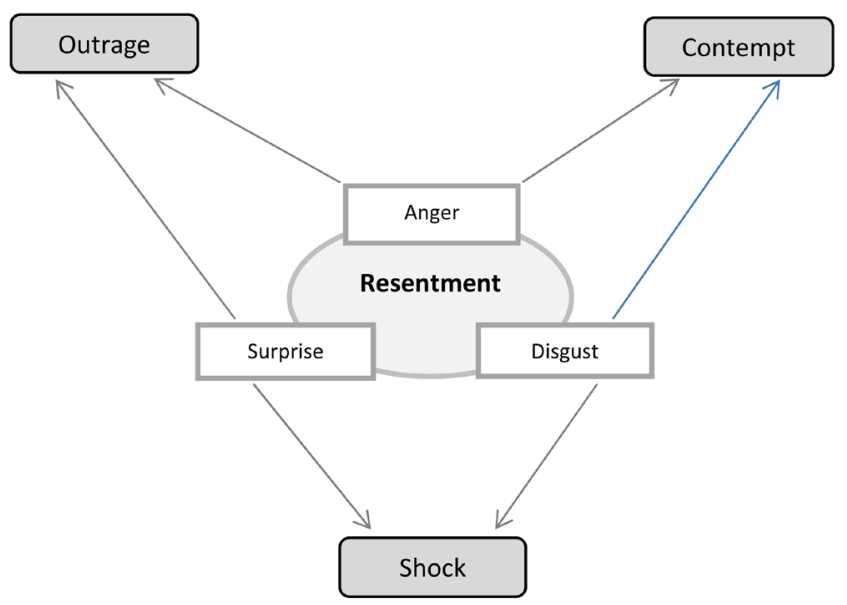

Figure 2. Proposed primary and secondary emotions of resentment.

brutalized by others. The anger within resentment "strives to get even, inflicts one hurt for another, ... [and] asserts one's personal power over anything that challenges it" (Diamond, 1996: p. 271). Such anger will take the form of a desire for the misery of the violator, together with an aversion to his happiness (Hume, [1739] 1978: p. 382). Hume saw anger as a response to suffering, pain, frustration, injury, and wrong inflicted by others which instills a desire to act in the moral role of punisher. Resentment, Hume ([1748] 1986: pp. 218-227) argued, strives to make itself known and is desired not for any hedonic pleasure but for itself. As summarized by Baier (1980: p. 138), Hume argued that, "Resentment is not simply anger, it is the form anger takes when it is provoked by what is seen as a wrong, and when the striking back which is desired is seen as punishment". Anger is interior to the very definition of resentment, which is "a feeling of ill will, bitterness, or anger against a person or thing" (Oxford online dictionary: meaning 1a).

The perception that one has received undeserved harmful treatment by others, and deserves better, can be a source of a deep and persisting anger. Those who experience childhood abuse are apt to develop a bitter resentment about having been mistreated and unloved, which creates a thirst for retribution. Pincus (2002) sees an anger-infused, even seething, intense, and enduring resentment, fueled by a sense of worthlessness, as increasing individuals' propensity for murder and rape, which become-although often misdirected and precipitated by a mild slight-crimes of retribution. Such deep resentment, Pinkus argues, leads to 1) seeing the slightest indifference as a global disrespect, 2) reduces capacity for self-control, and 3) leads to misinterpretation or distortion of social signals as shameful rejection (see also TenHouten, 2017a: pp. 105-121).

\section{Management and Control of Anger}

Aristotle, in discussing anger, concerned himself with what today would be called "emotion management" (Bolton, 2005) or "emotional self-regulation" (Gross \& Thompson, 2007; Haver, Akerjordet, \& Furunes, 2013). Aristotle ad- 
vised that emotions should be selectively invoked in response to one's ongoing social relationships. Aristotle ([355 BCE] 2002: p. 150) wrote, “Anyone can become angry - that is easy. But to be angry with the right person, to the right degree, at the right time, for the right purpose, and in the right way-that is not easy". Aristotle's analysis of emotion and character presented in his Rhetoric clearly showed that anger is effective only if adequately cognitively controlled, where the cognitive task is to accurately evaluate the ongoing social situation. Konstan (2007) suggests that Aristotle's notion of anger is quite foreign to modern notions. Yet, Aristotle's understanding of anger corresponds closely to contemporary emotions researchers, who conceptualize anger in terms of detecting and responding to a challenge to one's rightful place in the social world.

Aristotle also suggested that an individual might gain an advantage in a social encounter by not responding with anger even when such a response would be regarded as a "natural" reaction. The ancient Greeks grasp of anger was so profound that anger emerged from antiquity as the best understood of all the emotions (see Fortenbaugh, [1975] 2002; Braund \& Most, 2003; Graver, 2007; Kons$\tan , 2007:$ pp. 41-76). While we see uncontrolled anger as harmful and destructive, we accept the expression of legitimate anger, along with outrage and contempt, as justifiable sociomoral emotions. As Aristotle ([355 BCE] 2002: p. 1126a5) stated, "Those who are not angry at the things they ought to be angry at are thought to be fools". In the Aristotelian view, moderation of anger is necessary for the attainment of eudaimonia, the happiness that derives from becoming a fully flourishing, self-possessed human being, able to live in harmonious equilibrium in all spheres of being and with opposing forces, including love and hate, power and impotence, creation and destruction.

Effective anger management requires the development of patience, an aspect of mental maturity. The experience of anger can compress one's time perspective, potentially rendering one overly eager to act, perhaps seeking a final "showdown" with an adversary or leaping to a rapid, risky, and impulsive response to a decision. Anger discounts the value of the future and truncates perceived ongoing transgressions. When brain processes speed up, time seems to slow down. The temporal compression accompanying a feeling of anger can be countered through the cultivation of patience, which Buddhist philosopher Dalai Lama (1997) insightfully sees, together with tolerance, as an antidote to anger. Tolerance means not retaliating against an actual or perceived transgression; it requires a settled temperament, one not easily perturbed. Three attributes of tolerance contribute to the management and control of anger: 1) Tolerance based on acceptance of pain and hardship as natural, unavoidable facts of existence enables one to empathize with, and feel compassion for, one's adversary in an angry encounter. 2) Tolerance is enhanced through understanding that the actions of others are determined by a complex network of causes, both proximate and distal, which are outside of an angry individual's full understanding. Anger-another's or one's own-is never a matter of simple blame or an isolatable 
cause, for nothing governs itself fully. And 3), tolerance of injury to oneself caused by the action of another, through recognition that easily angered individuals lack cognitive control of their emotions, can improve individuals' anger management. Thus executive-level cognitive processes can nurture patience and contribute to effective anger management. The attainment of top-down cognitive control of anger enables firm and steadfast reactions in adverse situations. Patience and tolerance in the face of others' anger are signs, not of weakness or meekness, but rather of inner mental strength.

Even the healthiest of persons occasional experience a state of anger. It is much less healthy to find oneself in a nearly continuous state of anger, which can be called trait anger, as if being angry has become an integral part of one's personality, character, and being. Such angry people, those suffering from trait anger, run the risk of looking ridiculous to observers, and even to their anger's target, insofar as their responses are out of all proportion to the proximate provocation which triggered their latest outburst of anger. It will appear that the angry response is far too extreme, that it has exaggerated whatever hurt or insult might have just taken place. For example, changing lanes while driving, which inadvertently blocks another driver, on occasion triggers a rage in another driver which is hard to fathom, as if the very manhood of the putative "victim" is at stake. But such an enraged response hardly succeeds in signifying social power. As Greene (1998: p. 329) wryly observes, "The truth is the opposite. Rage is not power, it is a sign of helplessness. People might be temporarily cowed by your tantrums, but in the end, they lose respect for you. They also realize that they can easily undermine a person with so little self-control".

As an enduring aspect of one's orientation to the world, trait anger can last for months or years, across various context and situations. It can be unstable and disrupting and exaggerated beyond whatever hurt or insult might have taken place. An anger outburst over a minor transgression can thus be less personal than it appears, if its causes are temporally distal, or related to a chain of remembered social encounters which "long predate the present moment" (Greene, 1998: p. 329). Contemporary study of anger and aggression has shown that distally-motivated anger has diverse etiologies, including childhood abuse or compromised socialization. Individuals experiencing trait anger, for example, typically have at least one very angry or aggressive parent, so that trait anger is sometimes transmitted intergenerationally (Conger et al., 2003).

For individuals whose anger is episodic or persistent, and who can be said to experience anger as a personality trait, anger can assume highly pathological forms (DiGiuseppe \& Tafrate, 2007). Yet not all anger is pathological, as many individuals in their everyday social lives experience an occasional state of anger, which is typically of a transient nature, lasting minutes, an hour, perhaps a day. An angry mood often lasts longer than an emotional state of anger and can provide an "affective background" or "emotional color" (Davidson, 1995) lasting for days or weeks. Such an angry mood can trigger thoughts of revenge directed to- 
ward the source of the anger and can possibly stimulate depressive rumination. In trait anger, being angry has become an integral and nearly continuous aspect of personality and character, often starting early in childhood.

While anger is a basic emotion, and is widely shared in the animal kingdom, there are substantial cultural differences governing its expression and management. There are also differences within cultures (Marsh, Elfinbine, \& Ambady, 2003) and civilizations as they evolve and develop. Elias ([1939] 2000: pp. 161-182) described variations in aggressive expression of anger and other emotions in Western civilization Elias described these differences as minor in comparison to changes in the "civilized" nations at different stages of their development. Anger, and aggressiveness, while exuberantly displayed in Europe in the ancient world and during the Middle Ages, has been greatly subdued because of greater dependence of individuals on each other and on the mechanization of warfare. In medieval warfare, the release of hostile affect was open, savage, uninhibited, enjoyed as in the mutilation and torture of prisoners, as was the rapine hunting of animals and people. Beyond the zeal for violence of the warrior class, the weapons of money and knives stimulated the burgher class to "robbery, fighting, pillage, family feuds" as essential processes in the life of the town (Elias, [1939] 2000: p. 166). Violence was freely vented, openly and directly, but today we are shocked by displays of senseless violence, and aggressive displays of anger are, in comparison, subdued, moderate, and calculated. The taming of anger and other potentially volatile emotions was hardly realized with the advent of the modern era, and is a continuing process (Stearns \& Stearns, 1986).

While anger of mild intensity can focus the mind and enhance analytic processing (Moons \& Mackie, 2007), when the experience of anger is intense, at the level of rage, fury, or wrath, anger can disrupt cognitive functioning (Zillman, 1983). Deep anger can lead to simplified information processing and the making of black-and-white judgments (White, 1968) and to a kind of tunnel vision focused on the anger-inducing cues produced by the perpetrator of negative events, to the exclusion of other considerations. While intensely angry individuals freely express their grievances (Tedeschi \& Felson, 1994), they tend to do so in an inarticulate manner, and are typically unable to develop strategies for handling the precipitating event, and more generally for conflict resolution (Tedeschi, 2001: p. 119).

\section{Family Resemblance versus Hierarchical Classification}

Russell \& Fehr (1994) argue that anger is a category, a folk-concept or folk-taxonomy by which individuals categorize a vaguely defined, or "fuzzy", set of terms. They evaluate the "subcategories" of anger proposed by numerous emotions researchers, and present an inventory of terms that have differing degrees of membership in the category of anger. They present subject's ratings for 32 subcategories of anger, wherein the terms "fury", "rage", "mad", and "anger at self" fit the best, and "disgust", "depression", "sorrow", and "fear" fit the 
worst. While the best-fitting term indeed describe anger, the worst do not: Disgust, sorrow, and fear are, in Plutchik's and Ekman's (1992) classifications, primary emotion, and depression is clearly not an emotion. Other terms refer to anger-relate forms of behavior that might reveal anger but are not emotions: Included here are terms such as "violent". "fighting", and "yelling". Other terms, such as "jealousy" and "disappointment", would appear to be emotions that are not linked to anger. Yet other terms, such as "hate" and "resentment", clearly involve anger, but are not subcategories of anger, because they would appear to involve other emotion as well.

Thus, while the Russell-Fehr model views emotions such as aggressiveness, sullenness, and resentment as subcategories of anger, we rather contend that anger is an embedded subcategory of various secondary- or tertiary-level emotions. We claim that anger is not a broad term including various subcategories but a primary emotion that can mix with the other primary emotions and with secondary emotions. The viability of this claim can be demonstrated only by presenting a classification. A tentative classification of the 28 emotions of anger is shown in Table 1. Explanations for these interpretations are beyond the scope of this brief essay.

\section{Discussion}

Because of its deep evolutionary roots, and its likely universality across human cultures, anger is widely regarded as a basic or primary emotion. The utility of the notion of primary emotions depends on classification. If all emotions exist sui generis, as most psychological constructivists and social constructivists believe, then emotions-classification is not possible. However, if the primary emotions can mix, combine, or be simultaneously activated, to form more complex emotions, then classification of the emotions becomes possible, and we can conceptualize anger as embedded in secondary emotions, pairings of primary emotions, and in tertiary emotions. If we assume Plutchik's inventory of eight primary emotions as adaptive reactions to basic problems of life (Figure 1), then there must be 28 secondary emotions and 56 tertiary emotions (and 92 in all), with 7 of the secondary emotions and 21 of the tertiary emotions including anger as a primary-emotion component. This classification of emotions involving anger is, of course, tentative, but is sufficiently developed to suggest that complex emotions do not merely bear a family resemblance to emotions and are in this way secondary to anger, as in the Russell-Fehr formulation.

We have conceptualized anger as a goal-directed, approach-oriented, adaptive reaction to individual's place in social networks and social relationship, especially those that involve competition for resources and opportunities and the struggle for dominance in social hierarchies (TenHouten, 2017c). In social and affective neuroscience, studies are largely confined to just six primary emotions-anger, fear, sadness, joy-happiness, disgust, and surprise (the latter primarily in use of the Donchin oddball paradigm in evoked-potential studies). But 
Table 1. Anger embedded in 28 complex emotions, (a) 7 secondary and (b) 21 tertiary.

(a)

\begin{tabular}{|c|c|c|}
\hline \multicolumn{3}{|c|}{ SECONDARY EMOTIONS OF ANGER } \\
\hline & Primary Emotional Components & Secondary Emotions \\
\hline 1. & Anger \& Acceptance & $=$ Arrogance, haughtiness \\
\hline 2. & Anger \& Joy & $=$ Pride \\
\hline 3. & Anger \& Anticipation & $=$ Aggressiveness \\
\hline 4. & Anger \& Disgust & $=$ Contempt \\
\hline 5. & Anger \& Sadness & $=$ Sullenness, Balefulness \\
\hline 6. & Anger \& Fear & $=$ Frozenness (tonic immobility) \\
\hline 7. & Anger \& Surprise & $=$ Outrage, indignation, umbrage, pique \\
\hline
\end{tabular}

(b)

\begin{tabular}{|c|c|c|c|}
\hline \multicolumn{4}{|c|}{ TERTIARY EMOTIONS OF ANGER } \\
\hline & $\begin{array}{l}\text { Primary Emotional } \\
\text { Components }\end{array}$ & $\begin{array}{c}\text { Primary-Secondary } \\
\text { Combinations }\end{array}$ & Tertiary Emotions \\
\hline 8. & Anger \& (Acceptance \& Joy) & $=$ Anger \& Self-Love & $=$ Pridefulness \\
\hline 9. & Anger \& (Acceptance \& Anticipation) & $=$ Anger \& Fatalism & $=$ Confidence \\
\hline 10. & Anger \& (Acceptance \& Disgust) & $=$ Anger \& Ambivalence & $=$ Exasperation \\
\hline 11. & Anger \& (Acceptance \& Sadness) & $=$ Anger \& Resignation & $=$ Sulkiness, Surliness \\
\hline 12. & Anger \& (Acceptance \& Fear) & $=$ Anger $\&$ Submissiveness & $=$ Helplessness \\
\hline 13. & Anger \& (Acceptance \& Surprise) & $=$ Anger \& Curiosity & $=$ Nosiness \\
\hline 14. & Anger \& (Joy \& Anticipation) & $=$ Anger \& Optimism & $=$ Ambitiousness \\
\hline 15. & Anger \& (Joy \& Disgust) & $=$ Anger $\&$ Derisiveness & $=$ Ruthlessness \\
\hline 16. & Anger \& (Joy \& Sadness) & $=$ Anger $\&$ Bittersweetness & $=$ Recrimination \\
\hline 17. & Anger \& (Joy \& Fear) & $=$ Anger \& Guilt & $=$ Reproachfulness \\
\hline 18. & Anger \& (Joy \& Surprise) & $=$ Anger \& Delight & $=$ Maliciousness \\
\hline 19. & Anger \& (Anticipation \& Disgust) & $=$ Anger \& Cynicism & $=$ Disdainfulness \\
\hline 20. & Anger \& (Anticipation \& Sadness) & $=$ Anger \& Pessimism & $=$ Vengefulness \\
\hline 21. & Anger \& (Anticipation \& Fear) & $=$ Anger \& Anxiety & $=$ Apprehensiveness \\
\hline 22. & Anger \& (Anticipation \& Surprise) & $=$ Anger \& Confusion & $=$ Agitation \\
\hline 23. & Anger \& (Disgust \& Sadness) & $=$ Anger \& Loneliness & $=$ Bitterness \\
\hline 24. & Anger \& (Disgust \& Fear) & $=$ Anger \& Repugnance & $=$ Hatred \\
\hline 25. & Anger \& (Disgust \& Surprise) & $=$ Anger $\&$ Shock & $=$ Resentment \\
\hline 26. & Anger \& (Sadness \& Fear) & $=$ Anger \& Shame & $=$ Disparagement \\
\hline 27. & Anger \& (Sadness \& Surprise) & $=$ Anger $\&$ Disappointment & $=$ Envy \\
\hline 28. & Anger \& (Fear \& Surprise) & $=$ Anger \& Alarm & $=$ Defensiveness \\
\hline
\end{tabular}

for sociology, anthropology, political science, and more generally the social sciences, the emotions key to understanding the relationship between mind and society include the entire spectrum of the emotions, for individual and collective 
participation in social life cannot be understood apart from complex emotions such as jealousy, envy, resentment, discouragement, disappointment, dread, worry, despair, delight, confidence, ruthlessness, sanguinity, bliss, and so forth. The basic argument made here, focusing on anger, is that we must understood these complex social emotions not as subcategories of the most basic emotions, but rather as emergent from combinations of primary and secondary emotions.

\section{Conclusion}

Prominent scholars have argued that emotions cannot be classified. In philosophy, Spinoza ([1677] 1957: p. 63) opined that, "the emotions may be compounded one with another in so many ways, and so many variations may arise therefore, as to exceed all possibility of computation". In sociology, Durkheim \& Mauss ([1903] 1963: pp. 86-87) reached the remarkable conclusion that all social classifications are ultimately based on sentiments, and that the "emotional value of notions ... is the dominant characteristic in classification". At the same time, they lamented, "States of an emotional nature ... mingle their properties in such a way that they cannot be rigorously categorized". Why such pessimism? One limitation was that, as languages and cultures developed, terms used to describe affective states were broad indeed, and included more than one emotion. Anger is no exception. The root term angh-includes in its meaning "grief" and "sorrow", which today are recognized as descriptors of a distinct emotion, sadness. We have seen that anger and sadness are related and can provide for alternative coping mechanisms and affective strategies of leadership. But now it is widely agreed that anger and sadness are different emotions. For Plutchik, anger is the adaptive reaction to the positive experience of hierarchy; sadness, the reaction to the negative experience of temporality. While anger and sadness are very different emotions, they can occur together following an unfortunate turn in a social relationship and can be components of an affective response style, for example, of an incumbent of a position of social power (Schwarzmüller et al., 2017). When anger and sadness occur together, the resulting secondary emotions are classified as a baleful state of sullenness.

Despite gloomy pronouncements regarding classification, and constructivist views that ignore many contemporary discoveries, we hold that there exists a set of basic, or elementary, emotions with deep evolutionary roots, existing as natural kinds, which Plutchik might well have correctly identified six decades ago. If so, then the number of more complex emotions that can be formed from the most primordial emotions is not, as Spinoza believed, beyond all possible computation. The only way to resolve the ongoing debate among emotions researchers is to produce as viable classification. Table 1 shows a classification of 8 primary emotions, all 28 secondary emotions, and 21 of the hypothesized 56 tertiary emotions. By classification of the emotions, the sociology and anthropology of emotions will be better equipped to understanding everyday social interactions. This task has yet to been taken up in social neuroscience, in part because 
complex emotions such as bliss, despair, and hatred cannot be ethically evoked in a laboratory setting and subjected to neurometric measurement methodologies. The study of the most complex and deepest emotions presents itself as a project for the sociology of emotions. Of course, emotions are socially constructed, and somewhat differently in different cultures and civilizations, but this by no means negates the reality that the most basic emotions have an evolved neuroanatomical basis. Classifying the complex emotions which lie at the heart of everyday social life does not at all reduce emotions to a lower, neurophysiological level; it rather expands the potential scope of the sociology and anthropology of emotions. In the study of the complex affective states involved in social relations and social relationships, it will be helpful, even necessary, to distinguish between complex emotions and affective states that might be important but are not emotions, such as trust, suspicion, hurt, gratification, pity, compassion, argumentativeness, suspiciousness, hostility, impatience, pleasure, peevishness, serenity, and beyond.

\section{References}

Adams, R. B. Jr., Ambady, M., Macrae, C. M., \& Kleck, R. E. (2006). Emotional Expressions Forecast Approach-Avoidance Behavior. Motivation and Emotion, 30, 177-186. https://web.stanford.edu/group/ipc/pubs/2006Adams.pdf https://doi.org/10.1007/s11031-006-9020-2

Aristotle [355 BCE] (2002). Nicomachean Ethics (Tr. J. Sacks). Newbury, MA: Focus Publishing/R. Pullins.

Averill, J. (1982). Anger and Aggression: An Essay on Emotion. New York, NY: Springer-Verlag. https://doi.org/10.1007/978-1-4612-5743-1

Baier, A. C. (1980). Hume on Resentment. Hume Studies, 6, 133-149. http://www.humesociety.org/hs/about/terms.html https://doi.org/10.1353/hms.2011.0612

Bailey, F. G. (1983). The Tactical Uses of Passion: An Essay on Power, Reason, and Reality. Ithica, NY: Cornell University Press.

Ben-Ze'ev, A. (2000). The Subtlety of Emotions. Cambridge, MA: The MIT Press.

Berkowitz, L. (1990). On the Formation and Regulation of Anger and Aggression: A Cognitive-Neoassociationistic Analysis. American Psychologist, 45, 494-503. https://www.mcbi.nih.gov/pubmed/2186678 https://doi.org/10.1037/0003-066X.45.4.494

Berkowitz, L. (1993). Toward a General Theory of Anger and Emotional Aggression: Implications of the Cognitive-Neoassociationistic Perspective for the Analysis of Anger and Other Emotions. In Jr. R. S. Wyer, \& T. K. Srull (Eds.), Perspectives on Anger and Emotion: Advances in Social Cognition (Vol. 6, pp. 1-46). Hillsdale, NJ: Lawrence Erlbaum.

Bolton, S. C. (2005). Emotion Management in the Workplace. Basingstoke: Palgrave.

Braund, S., \& Most, G. W. (2003). Ancient Anger: Perspectives from Homer to Galen. Cambridge: Cambridge University Press.

Cacioppo, J. T., \& Bernston, G. (1994). Relationship between Attitudes and Evaluative Space: A Critical Review, with Emphasis on the Separability of Positive and Negative Substrates. Psychological Bulletin, 115, 401-423. 
Carver C. S., \& Harmon-Jones, E. (2009). Anger Is an Approach-Related Affect: Evidence and Implications. Psychological Bulletin, 135, 183-204.

https://www.ncbi.nlm.nih.gov/pubmed/19254075 https://doi.org/10.1037/a0013965

Clore, G. L., Ortony, A., Dienes, B., \& Fujity, F. (1993). Where Does Anger Dwell? In R. S. Wyer, \& T. K. Srull (Eds.), Perspectives on Anger and Emotion: Advances in Social Cognition (Vol. 6, pp. 57-87). Hillsdale, NJ: Lawrence Erlbaum.

Coan, J., A., Allen, J. J. B., \& Harmon-Jones, E. (2001). Voluntary Facial Expression and Hemispheric Asymmetry over the Frontal Cortex. Psychophysiology, 38, 912-925. https://www.ncbi.nlm.nih.gov/pubmed/12240668 https://doi.org/10.1111/1469-8986.3860912

Conger, R. D., Neppi, T., Kim, K. J., \& Scaramella, L. (2003). Anger and Aggressive Behavior across Three Generations: A Prospective, Longitudinal Study of Parents and Children. Journal of Abnormal Child Psychology, 31, 143-160.

https://www.ncbi.nlm.nih.gov/pubmed/12735397

https://doi.org/10.1023/A:1022570107457

Dalai Lama (Tenzi Gyatso) (1997). Healing Anger: The Power of Patience from a Buddhist Perspective (Tr. G. T. Jinpa). Ithica, NY: Snow Lion Publications.

Darwin, C. [1872] (1965). The Expression of the Emotions in Man and Animals. Chicago, IL: The University of Chicago Press.

Davidson, R. J. (1995). Cerebral Asymmetry, Emotion, and Affective Style. In R. J. Donaldson, \& K. Hugdahl (Eds.), Brain Asymmetry (pp. 361-387). Cambridge, MA: The MIT Press.

Davis, A. (1983). Leadership, Love, and Aggression. San Diego, CA: Harcourt Brace Jovanovich.

Depue, R. A., \& Iacono, W. G. (1989). Neurobehavioral Aspects of Affective Disorders. Annual Review of Psychology, 40, 457-492.

https://www.ncbi.nlm.nih.gov/pubmed/2648983

https://doi.org/10.1146/annurev.ps.40.020189.002325

Diamond, S. A. (1996). Anger, Madness, and the Diamonic: The Psychological Genesis of Violence, Evil, and Creativity. Albany, NY: State University of New York Press.

DiGiuseppe, R., \& Tafrate, R. C. (2007). Understanding Anger Disorders. New York, NY: Oxford University Press.

Durkheim, É., \& Mauss, M. [1903] (1963). Primitive Classification (Tr. R. Needham). Chicago, IL: The University of Chicago Press.

Ekman, P. (1992). An Argument for Basic Emotions. Cognition and Emotion, 6, 169-200. https://www.tandfonline.com/doi/abs/10.1080/02699939208411068 https://doi.org/10.1080/02699939208411068

Elias, N. [1939] (2000). The Civilizing Process: Sociogenetic and Psychogenetic Investigation (Tr. E. Jepcott). Oxford: Blackwell Publishing.

Finman, R., \& Berkowitz, L. (1989). Some Factors Influencing the Effect of Depressed Mood on Anger and Overt Hostility toward Another. Journal of Research in Personality, 23, 70-84. https://doi.org/10.1016/0092-6566(89)90034-2

Fiske, A. P. (1991). Structures of Social Life: The Four Elementary Forms of Human Relations. New York, NY: Free Press.

Fiske, A. P. (2004). Four Models of Constituting Relationships: Consubstantial Assimilation; Space, Magnitude, Time, and Force; Concrete Procedures; Abstract Symbolism. In N. Haslam (Ed.), Relational Models Theory: A Contemporary Overview (pp. 61-146). 
Mahwah, NJ: Lawrence Erlbaum.

Fortenbaugh, W. W. [1975] (2002). Aristotle on Emotion: A Contribution to Philosophical Philosophy, Rhetoric, Poetics, and Ethics (2nd ed.). London: Gerald Duckworth.

Frijda, N. H. (1986). The Emotions. Cambridge: Cambridge University Press.

Gaylin, W. (1989). The Rage Within: Anger in Modern Times. New York, NY: Penguin Books.

Grant, P. R. (2008). The Protest Intentions of Skilled Immigrants with Credentialing Problems: A Test of a Model Integrating Relative Deprivation Theory with Social Identity Theory. British Journal of Social Psychology, 47, 687-705.

https://www.ncbi.nlm.nih.gov/pubmed/18166140 https://doi.org/10.1348/014466607X269829

Graver, M. R. (2007). Stoicism \& Emotion. Chicago, IL: The University of Chicago Press. https://doi.org/10.7208/chicago/9780226305202.001.0001

Greene, R. (1998). The 48 Laws of Power. New York, NY: Penguin Books.

Gross, J. J., \& Thompson, R. A. (2007). Emotion Regulation: Conceptual Foundations. In J. J. Gross (Ed.), Handbook of Emotion Regulation (pp. 3-24). New York, NY: Guilford Press.

Harmon-Jones, C., Schmeichel, B. J., Mennitt, E., \& Harmon-Jones, E. (2011). The Expression of Determination: Similarities between Anger and Approach-Related Positive Affect. Journal of Personality and Social Psychology, 100, 172-181.

https://www.ncbi.nlm.nih.gov/pubmed/20853981 https://doi.org/10.1037/a0020966

Haver, A., Akerjordet, K., \& Furunes, T. (2013). Emotion Regulation and Its Implications for Leadership: An Integrative Review and Future Research Agenda. Journal of Leadership \& Organizational Studies, 20, 287-303.

https://search.proquest.com/docview/1459339065?accountid=14512 https://doi.org/10.1177/1548051813485438

Haviland, J. M, \& Lelwica, M. (1987). The Induced Affect Response: 10-Week-Old Infants' Responses to Three Emotion Expressions. Developmental Psychology, 23, 97-104. https://doi.org/10.1037/0012-1649.23.1.97

He, J., Degnan, K. A., McDermott, J. M., Henderson, H. A., Hane, A. A., Xu, Q., \& Fox, N. A. (2010). Anger and Approach Motivation in Infancy: Relations to Early Childhood Inhibitory Control and Behavioral Problems. Infancy, 15, 246-269.

https://www.ncbi.nlm.nih.gov/pubmed/25705134 https://doi.org/10.1111/j.1532-7078.2009.00017.x

Heller, W., Nitschke, J. B., \& Miller, G. A. (1998). Lateralization in Emotion and Emotional Disorders. Current Directions in Psychological Science, 7, 3-27.

Hume, D. [1739] (1978). A Treatise of Human Nature (2nd ed.). Oxford: Clarendon.

Hume, D. [1748] (1986). Enquiries Concerning the Human Understanding and Concerning the Principles of Morals (3rd ed.). Oxford: Clarendon.

Izard, C. (1980). The Emergence of Emotions and the Development of Consciousness in Infants. In J. M. Davidson, \& R. J. Davidson (Eds.), The Psychobiology of Consciousness (pp.193-216). New York, NY: Plenum Press.

Konstan, D. (2007). The Emotions of the Ancient Greeks: Studies in Aristotle and Classical Literature. Toronto: University of Toronto Press.

LaFollette, H. (1995). Personal Relationships: Love, Identity, and Morality. Oxford: Blackwell Publishers.

Lazarus, R. (1999). Hope: An Emotion and a Vital Coping Resource against Despair. So- 
cial Research, 66, 653-678.

Lerner, J. S., \& Tiedens, L. Z. (2006), Portrait of the Angry Decision Maker: How Appraisal Tendencies Shape Anger's Influence on Cognition. Journal of Behavioral Decision Making, 19, 115-137. https://onlinelibrary.wiley.com/doi/pdf/10.1002/bdm.515 https://doi.org/10.1002/bdm.515

Marsh, A. A., Elfinbein, H. A., \& Ambady, N. (2003). Nonverbal “Accents”: Cultural Differences in Facial Expressions of Emotion. Psychological Science, 14, 373-376. https://www.ncbi.nlm.nih.gov/pubmed/12807413 https://doi.org/10.1111/1467-9280.24461

Moons, W. G., \& Mackie, D. M. (2007). Thinking Straight while Seeing Red: The Influence of Anger on Information Processing. Personality and Social Psychology Bulletin, 33, 706-720. https://www.ncbi.nlm.nih.gov/pubmed/17440205 https://doi.org/10.1177/0146167206298566

Neufeldt, V., \& Guralnik, D. B. (1988). Webster's New World Dictionary of American English. New York, NY: Webster's New World.

Panksepp, J. (1998). Affective Neuroscience: The Foundations of Human and Animal Emotions. New York, NY: Oxford University Press.

Panksepp, J., \& Biven, L. (2012). The Archaeology of Mind: Neuroevolutionary Origins of Human Emotions. New York, NY: W. W. Norton \& Company.

Pincus, J. H. (2002). Base Instincts: What Makes Killers Kill. New York, NY: W. W. Norton.

Plutchik, R. (1958). Outlines of a New Theory of Emotion. Transactions of the New York Academy of Sciences, 20, 394-403. https://www.ncbi.nlm.nih.gov/pubmed/13556854 https://doi.org/10.1111/j.2164-0947.1958.tb00600.x

Plutchik, R. (1962). The Emotions: Facts, Theories, and a New Model. Lanham, MD: University Press of America.

Plutchik, R. (1970). Emotions, Evolution, and Adaptive Processes. In M. Arnold (Ed.), Feelings and Emotions: The Loyola Symposium (pp. 1-14). New York, NY: Academic Press. https://doi.org/10.1016/B978-0-12-063550-4.50007-3

Plutchik, R. (1980). Emotion: A Psychoevolutionary Synthesis. New York, NY: Harper \& Row.

Pratto, F., Sidanius, J., Stallworth, L. M., \& Malle, B. F. (1994). Social Dominance Orientation: A Personality Variable Predicting Social and Political Attitudes. Journal of Personality an Social Psychology, 67, 741-763.

https://search.proquest.com/docview/618602005? accountid=14512 https://doi.org/10.1037/0022-3514.67.4.741

Ratcliff, N. J., Bernstein, M. J., Cundiff, J. L., \& Vescio, T. K. (2012). Seeing Wrath from the Top (Through Stratified Lenses): Perceivers High in Social Dominance Orientation Show Superior Anger Identification for High-Status Individuals. Journal of Experimental Social Psychology, 48, 1373-1376.

https://www.sciencedirect.com/science/article/pii/S0022103112000972 https://doi.org/10.1016/j.jesp.2012.05.016

Rosenblatt, P. C., Jackson, D. A., \& Walsh, R. P. (1973). Coping with Anger and Aggression in Mourning. Omega: Journal of Death and Dying, 3, 271-284. https://search.proquest.com/docview/615889950?accountid=14512 https://doi.org/10.2190/MNMJ-G1QN-05U1-WVPA

Russell, J. A. (1980). A Circumplex Model of Affect. Journal of Personality and Social Psychology, 39, 1161-1178. https://www.researchgate.net/publication/235361517 https://doi.org/10.1037/h0077714 
Russell, J. A., \& Fehr, B. (1994). Fuzzy Concepts in a Fuzzy Hierarchy: Varieties of Anger. Journal of Personality and Social Psychology, 67, 186-205. https://www.ncbi.nlm.nih.gov/pubmed/7932061 https://doi.org/10.1037/0022-3514.67.2.186

Scheff, T. J., \& Retzinger, S. M. (1991). Emotions and Violence: Shame and Rage in Destructive Conflict. Lexington, MA: Lexington Books.

Schwarzmüller, T., Brosi, P., Spörrle, M., \& Welpe, I. M. (2017). It's the Base: Why Displaying Anger Instead of Sadness Might Increase Leaders' Perceived Power but Worsen Their Leadership Outcomes. Journal of Business and Psychology, 32, 691-709.

https://link.springer.com/article/10.1007/s10869-016-9467-4 https://doi.org/10.1007/s10869-016-9467-4

Shand, A. (1914). The Foundation of Character: Being a Study of the Tendencies of the Emotions and Sentiments. New York, NY: MacMillan Co.

Sidanius, J., \& Pratto, F. (2001). Social Dominance. Cambridge: Cambridge University Press.

Sloterdijk, P. (2006). Rage and Time: A Psychopolitical Investigation (Tr. M. Wenning). New York, NY: Columbia University Press.

Smith, H. J., Pettigrew, T. F., Pippin, G. M., \& Bialosiewicz, S. (2012). Relative Deprivation: A Theoretical and Meta-Analytic Review. Personality and Social Psychology Review, 16, 203-232. https://www.ncbi.nlm.nih.gov/pubmed/22194251 https://doi.org/10.1177/1088868311430825

Spinoza, B. de. [1677] (1957). The Ethics of Spinoza. New York, NY: Citadel Press.

Stearns, C. Z., \& Stearns, P. N. (1986). Anger: The Struggle for Emotional Control in American History. Chicago, IL: The University of Chicago Press.

Tedeschi, J. T. (2001). Social Power, Influence, and Aggression. In J. P. Forgas, \& K. D. Williams (Eds.), Social Influence: Direct and Indirect Processes (pp. 109-126). Philadelphia. PA: Psychology Press.

Tedeschi, J. T., \& Felson, R. B. (1994). Violence, Aggression, and Coercive Actions. Washington DC: American Psychological Association. https://doi.org/10.1037/10160-000

TenHouten, W. D. (2007). A General Theory of Emotions and Social Life. New York, NY: Routledge.

TenHouten, W. D. (2013). Emotion and Reason: Mind, Brain, and the Social Domains of Work and Love. New York, NY: Routledge.

TenHouten, W. D. (2016). The Emotions of Powerlessness. Journal of Political Power, 9, 83-121. https://doi.org/10.1080/2158379X.2016.1149308 https://www.tandfonline.com/doi/full/10.1080/2158379X.2016.1149308?src=recsys

TenHouten, W. D. (2017a). Alienation and Affect. New York, NY: Routledge.

TenHouten, W. D. (2017b). From Primary Emotions to the Spectrum of Affect: An Evolutionary Neurosociology of the Emotions. In A. Ibáñez, L. Sedeño, \& A. M. Garcia (Eds.), Neuroscience and Social Science: The Missing Link (pp. 144-167). New York, NY: Springer. https://doi.org/10.1007/978-3-319-68421-5_7

TenHouten, W. D. (2017c). Social Dominance Hierarchy and the Pride-Shame System. Journal of Political Power, 10, 94-114. https://www.tandfonline.com/doi/abs/10.1080/2158379X.2017.1285154 https://doi.org/10.1080/2158379X.2017.1285154

Termine, N. T., \& Izard, C. E. (1988). Infants' Response to their Mothers' Expressions of 
Joy and Sadness. Developmental Psychology, 24, 223-229.

https://search.proquest.com/docview/617440467? accountid=14512

https://doi.org/10.1037/0012-1649.24.2.223

Tiedens, L. Z. (2001). Anger and Advancement versus Sadness and Subjugation. Journal of Personality and Social Psychology, 80, 86-94.

https://www.ncbi.nlm.nih.gov/pubmed/11195894

https://doi.org/10.1037/0022-3514.80.1.86

Tiedens, L. Z., Ellsworth, P. C., \& Mesquita, B. (2000). Stereotypes about Sentiments and Status: Emotional Expectations for High- and Low-Status Group Member. Journal of Personality and Social Psychology, 26, 560-574.

https://www.scopus.com/record/display.uri?eid=2-s2.0-0034348878\&origin=inward\&t $\mathrm{xGid}=4 \mathrm{c} 70 \mathrm{~b} 41 \mathrm{e} 08071 \mathrm{~d} 5938 \mathrm{e} 41 \mathrm{fbb} 95 \mathrm{~cd} 0 \mathrm{ce} 0$ https://doi.org/10.1177/0146167200267004

Tomarken, A. J., \& Zald, D. H. (2009). Conceptual, Methodological, and Empirical Ambiguities in the Linkage between Anger and Approach: Comment on Carver and Harmon-Jones (2009). Psychological Bulletin, 135, 209-214.

https://www.ncbi.nlm.nih.gov/pubmed/19254077 https://doi.org/10.1037/a0014735

Van Kleef, G. A., \& Côte, S. (2007). Expressing Anger in Conflict: When It Helps and When It Hurts. The Journal of Applied Psychology, 92, 1557-1569.

https://www.ncbi.nlm.nih.gov/pubmed/18020796 https://doi.org/10.1037/0021-9010.92.6.1557

Van Kleef, G. A., De Dreu, C. K. W., Pietroni, D., \& Manstead, A. S. R. (2006). Power and Emotion in Negotiation: Power Moderates the Interpersonal Effects of Anger and Happiness on Concession Making. European Journal of Social Psychology, 36, 557-581. https://doi.org/10.1002/ejsp.320

Walton, S. (2004). A Natural History of Human Emotions. New York, NY: Grove Press.

White, R. K. (1968). Nobody Wanted War: Misperception in Vietnam and Other Wars. New York, NY: Doubleday.

Wickless, C., \& Kirsch, I. (1988). Cognitive Correlates of Anger, Anxiety, and Sadness. Cognitive Therapy and Research, 12, 367-377. https://link.springer.com/article/10.1007/BF01173304 https://doi.org/10.1007/BF01173304

Zillman, D. (1983). Arousal and Aggression. In R. G. Geen, \& E. I. Donnerstein (Eds.), Aggression: Theoretical and Empirical Reviews (Vol. 1, pp. 75-101). New York, NY: Academic Press. 